\title{
GEOREFERENCING ACCURACY ASSESSMENT OF PLÉIADES 1A IMAGES USING RATIONAL FUNCTION MODEL
}

\author{
H. Topan*, T. Taskanat, A. Cam \\ BEU, Engineering Faculty, Dept. of Geomatics Engineering, 67100, Zonguldak, Turkey - topan@beun.edu.tr, \\ alicam193@gmail.com, talhataskanat@gmail.com
}

KEY WORDS: Pléiades, georeferencing, figure condition, rational function model, undulating topography, Zonguldak test field

\begin{abstract}
:
This paper presents the first experience of georeferencing accuracy analysis of Pléiades 1A mono images. The Pléiades Constellation has been founded by CNES (The Centre National d'Etudes Spatiales - National Centre for Space Studies) consisting of Pléiades 1A\&1B, following the previous five sisters of SPOT series. CNES also organized a Pléiades Users Group following a world-wide invitation. The images investigated in this research were received as one of the member of this Group. A stereo-pair was evaluated on Zonguldak test field where the topography is mountainous and undulating overlapping urban, rural and forest landscapes. As a first experience, totally 22 ground control points (GCPs) already existing were marked on the images, and the bias compensated Rational Function Model (RFM) was carried out reaching \pm 0.8 pixel at the GCPs. The overall georeferencing accuracy was performed by the figure condition analysis (FCA), a new concept successfully applied to IKONOS, OrbView-3 and QuickBird images of the same test field. The range of figure condition is between \pm 0.3-2.7 pixels. These results were compared with the other images of three sensors mentioned above. Although a special GCP survey by GNSS has not been performed yet, these first results are satisfied for the highly accurate georeferencing of the Pléiades $1 \mathrm{~A}$ images.
\end{abstract}

\section{INTRODUCTION}

Following the five experiments via SPOT (Système Pour l'Observation de la Terre) series, a new constellation has been established by CNES (the Centre National d'Etudes SpatialesNational Centre for Space Studies). The first member of the constellation is Pléiades 1A launched in its sun- synchronous and almost circular orbit in 17th December 2011, and the other one, Pléiades 1B, has been launched in 2nd December 2012. This constellation is expected to serve until 2023 (Figure 1).

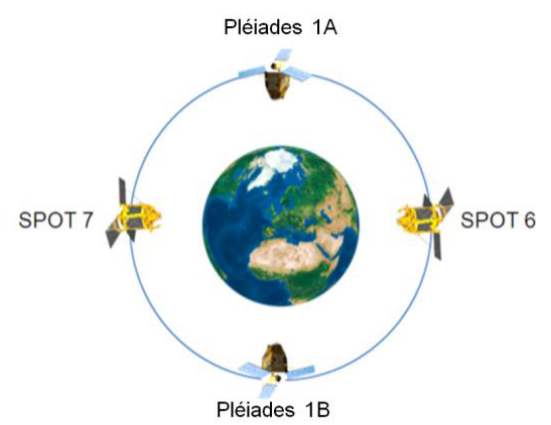

Figure 1. Pléiades 1A/1B \& SPOT 6/7 Constellation (Astrium-GEO 2012)

Pléiades is the first sub-meter earth observation satellite of Europe, and has been developed within the joint program ORFEO (Optical and Radar Federated Earth Observation) between France and Italy. So the French based optical experiences successfully proceeded by SPOT series since 1986 , and the Italian based microwave technology are combined for such a purpose. The Italian group has developed the COSMOSkyMed constellation within this program. Austria, Belgium,

\footnotetext{
* Corresponding author.
}

Spain and Sweden are the other countries to collaborate in the Pléiades system (Astrium-GEO 2012).

\subsection{Literature Review}

When the existing publications are reviewed, it can be summarized that Lamard et al. (2004), Baudoin (2004), Lussy et al. (2005), Baillarin et al. (2006), Baillarin et al. (2010), Panem et al. (2012), Gleyzes et al. (2012), and Boissin et al. (2012) define the system, and present the specifications; Lussy et al. (2005), J. M. Delvit et al. (2012), Lussy et al. (2012), Greslou et al. (2012) present the geometric properties; Lebegue et al. (2010), Blanchet et al. (2012), Lebègue et al. (2012), Latry et al. (2012), Fourest et al. (2012) and Poli et al. (2013) evaluate the radiometric quality; Delaunay et al. (2008) mentions about the image compression algorithms; Bernard et al. (2012) and Poli et al. (2013) focuses on the DEM (Digital Elevation Model) generation and validation; Flamanc and Maillet (2005) study the 3D city modelling using the simulated images; Lachérade et al. (2012) presents the in-flight calibration results, and Bignalet-Cazalet et al. (2012) experience the mosaicking performances. Beaumet et. al. (2011) also deal with the on-board decision making system within the frame of Pléiades. Astrium-GEO (2012) publishes the Pléiades Imagery User Guide for the end-users.

\subsection{Pléiades Users Group}

Astrium Services decided to establish a Pléiades Users Group at the $22^{\text {nd }}$ ISPRS (International Society for Photogrammetry and Remote Sensing) Congress in Melbourne, Australia, to offer opportunities to assess the utility of Pléiades data for applications and to provide users a forum to exchange their feedback about the uses and performances of Pléiades. An invitation has been announced until end of September 2012. 
The proposal prepared by some of the FUKAL (Turkish acronym of Photogrammetry-Remote Sensing and Geospatial Analysis Laboratory at Bülent Ecevit University) members has been accepted as one of the 120 projects selected from total 180 proposals.

The aims in our project is to evaluate Pléiades images with regard to the followings

1. Georeferencing accuracy,

2. Geometric and radiometric analysis,

3. Pan-sharpened image generation and quality assessment,

4. DSM (Digital Surface Model) and DEM generation and comparison via the reference DEMs,

5. Geospatial information based content analysis, and

6. Forest and environmental applications etc.

The following section mentions about the test site, data and georeferencing accuracy analysis.

\section{TEST SITE AND DATA}

\subsection{Test Site}

Since 2000s, various kind of aerial and spaceborne remotely sensed optical and microwave images are evaluated over Zonguldak (Turkey) test site. The main characteristics of this test site are its mountainous and undulating topography, dense forest and agricultural areas, various water bodies such as rivers, sea, and dams, open and underground mining areas, thermal power stations and iron and steel plants etc.. Zonguldak city centre was also constructed on this undulating mountainous topography (Figure 2). The readers can reach the publications about Zonguldak test site via FUKAL web (http://geomatik.beun.edu.tr/fukal/yayinlar.html).

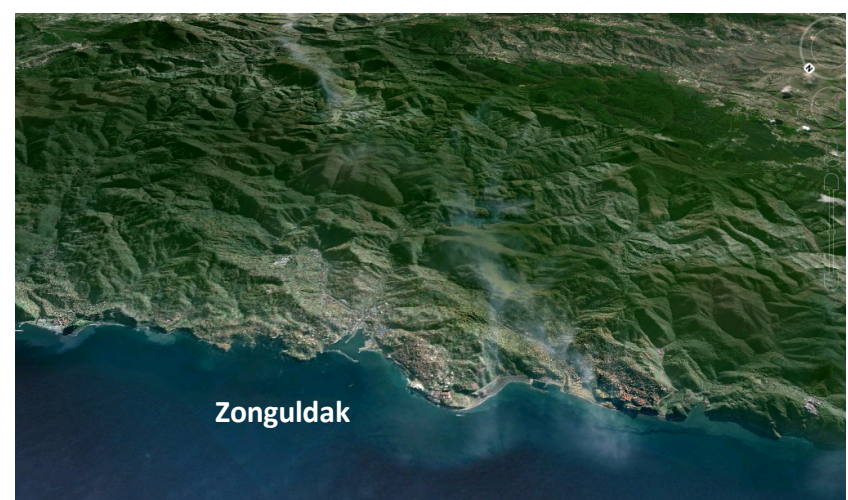

Figure 2. Zonguldak city centre and its hinterlands in Google Earth.

\subsection{Data Description}

Two sets of three-stereo images, totally six images, covering Zonguldak test sites were acquired both in panchromatic and four multispectral bands (blue, green, red and near infrared). Figure 3 illustrates the image acquisition and Table 1 presents the main characteristics. Because of the field survey for accurate GCP (Ground Control Point) collection via GNSS (Global Navigation Satellite System) observation has not been completed yet, only the images covering the same area imaged by IKONOS ( $1 \mathrm{~m}$ GSD), QuickBird (0.6 m GSD) and OrbView-3 (1 m GSD) sensors are evaluated, thanks to image- to-image GCP collection method. The readers might wonder the GSDs of IKONOS and OrbView-3 have wider than Pléiades has. Nevertheless, since the GCPs are obtained on the bare ground and symmetric objects, there is no significant precision-loss in our case. According to Kapnias et al. (2008), the GCP accuracy must be 3 times ( 5 times suggested) more precise than the target specification for the ortho-image, it is \pm 1 pixel $(0.7 \mathrm{~m})$ in our case. So the GCP accuracy with $\pm 3 \mathrm{~cm}$ is extremely enough for this aim. As a data distribution policy, if the image is larger than 2 gigabytes, the image is divided into four parts. Totally $23 \mathrm{GCPs}$ are pointed on the R1C1 part.

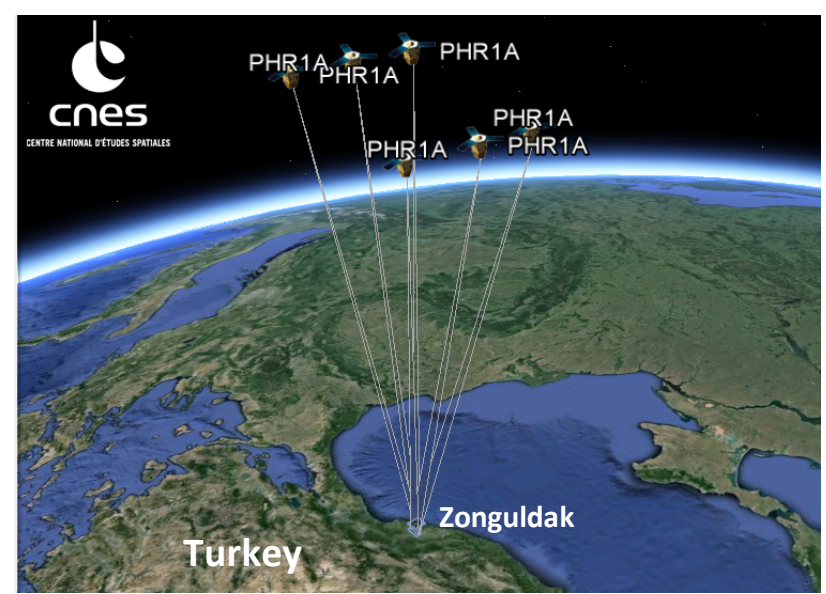

Figure 3. Image acquisition over Zonguldak test site (illustration at Google Earth).

\begin{tabular}{lr}
\hline Imaging time & $08: 55: 12.6$ \\
Azimuth $\left(^{\circ}\right)$ & 179.94 \\
Across-track ( ${ }^{\circ}$ ) & 4.54 \\
Along-track $\left(^{\circ}\right)$ & 4.55 \\
GSD (across-along & $0.70-0.71$ \\
track) (m) & \\
Size (rows) (pixel) & 32000 \\
Size (columns) (pixel) & 32000 \\
Sun azimuth ( ${ }^{\circ}$ ) & 152.63 \\
Sun elevation $\left(^{\circ}\right)$ & 59.10 \\
Image part & $\mathrm{R} 1 \mathrm{C} 1$ \\
\hline
\end{tabular}

Table 1. Main characteristics of the investigated image.

A DEM is also used as a source of FCP (Figure Condition Point) for the georeferencing analysis, generated from 1:2000 topographic maps. The accuracies of DEM data are about \pm 40 $\mathrm{cm}$ in planimetry and about $\pm 50 \mathrm{~cm}$ in height. The heights range sea level to $500 \mathrm{~m}$. Figure 5 illustrates the contour plot of the DEM.

\section{GEOREFERENCING ANALYSIS}

This initial experience on Pléiades images was performed on the mono image acquired in nadir view. At first, some evaluations were reported on the primary image distributed in geotiff format with WGS84 geographic coordinates.

\subsection{Initial Evaluation}

At first, the absolute georeferencing accuracy has been estimated as $\pm 56.6 \mathrm{~m}$ in East and $\pm 47.5 \mathrm{~m}$ in North direction. A systematic effect has been detected to the south-east 


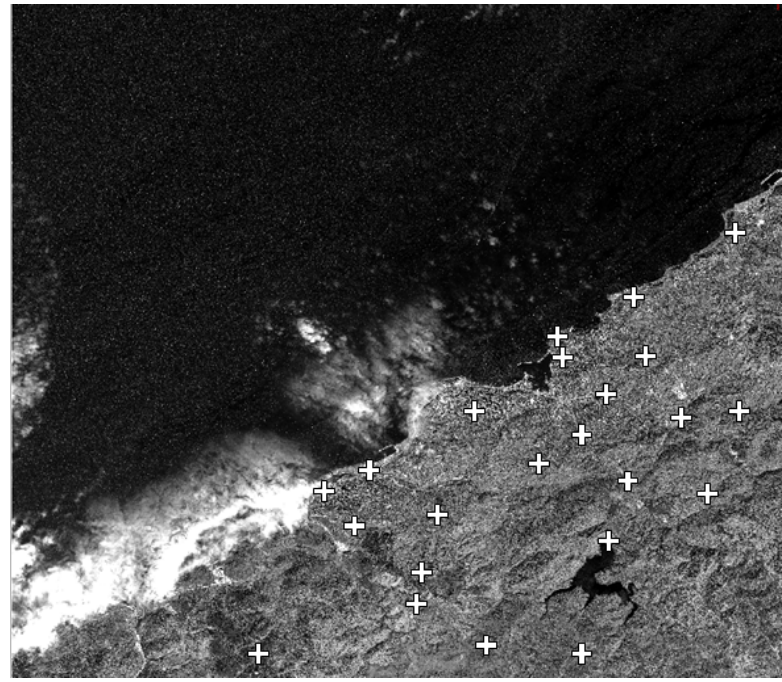

Figure 4. GCP distribution on Image-1.

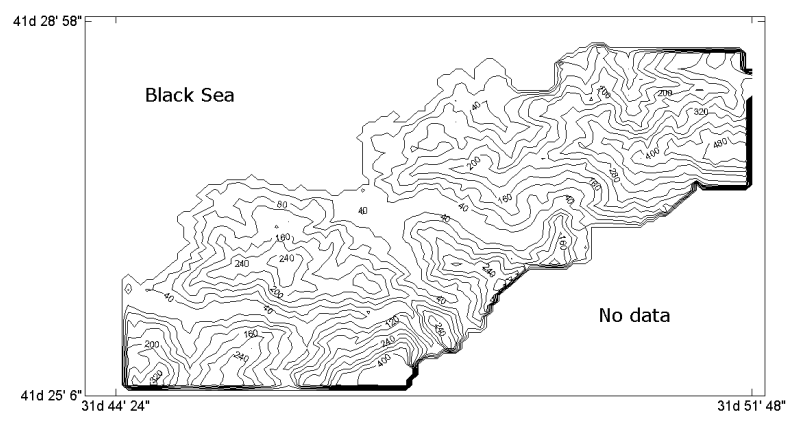

Figure 5. Contour plot of DEM generated from 1:2000 topographic maps. East and west coordinates are with WGS-84 geographic coordinates.

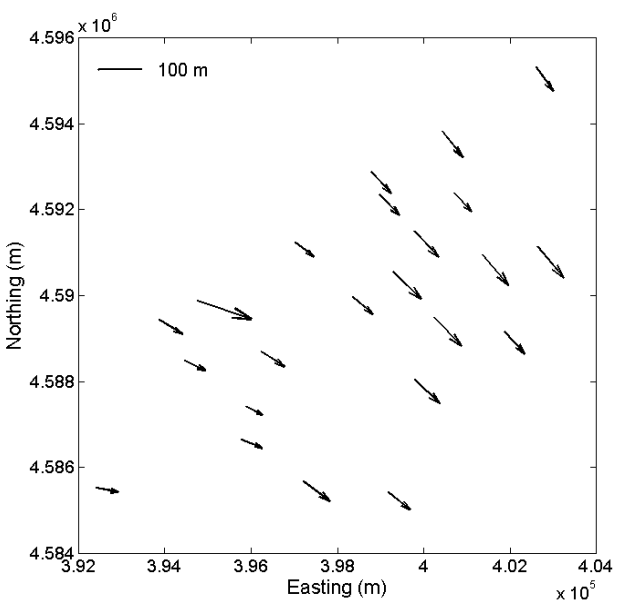

Figure 6. Absolute accuracy. Vector directions are from the geographic coordinates at image to the ones obtained by GNSS ( $\pm 56.6 \mathrm{~m}$ in East, $\pm 47.6 \mathrm{~m}$ in North).In this case, the standard deviation is estimated as \pm 7.4 pixels.

direction as illustrated in Figure 6. A few additional analyses have been done that, the relative positions of a point in the three stereo images are estimated in a planimetric shift between $\pm 51.5 \mathrm{~m}$ and $\pm 165.21 \mathrm{~m}$. This relative accuracy is recorded as about $\pm 260 \mathrm{~m}$ between two images taken in

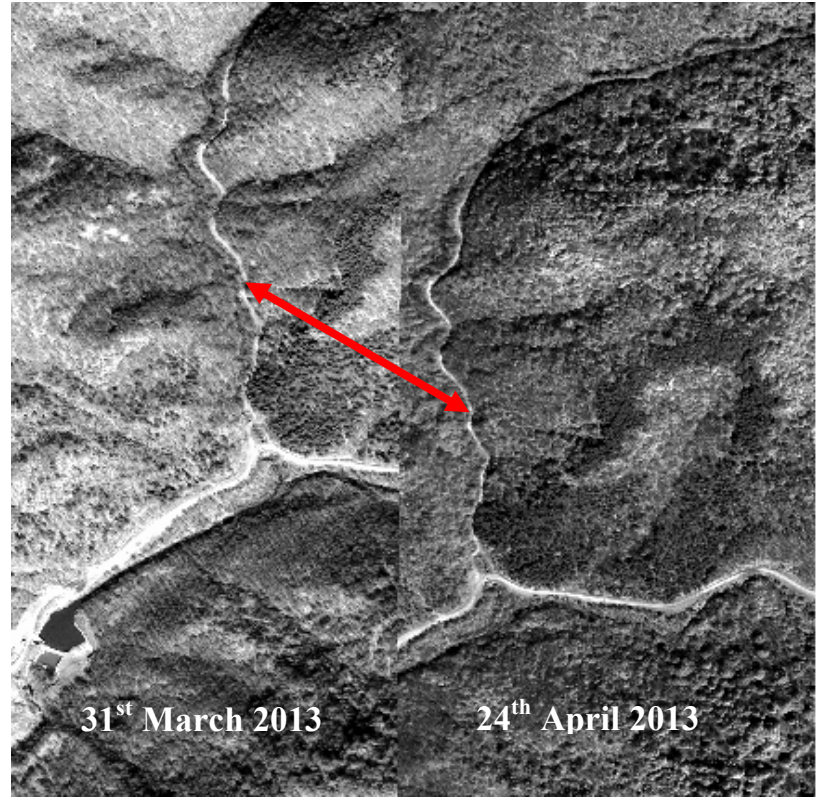

Figure 7. Systematic shift between two primary images. Magnitude of planimetric shift is about $\pm 260 \mathrm{~m}$.

different dates, i.e. $31^{\text {st }}$ March and $24^{\text {th }}$ April 2013 (Figure 7).

Nevertheless, such kind of shift can be recorded on the primary images, because the georeferencing accuracy is affected by the incidence angles and also by the instantaneous accuracy and precision of the imaging sensor and platform parameters. This shift is recorded as $\pm 58.25 \mathrm{~m}$ in East and $\pm 1.5 \mathrm{~m}$ in North at two IKONOS images acquired different dates.

\subsection{Georeferencing Accuracy}

Pléiades images are distributed with both direct and inverse RPCs (Rational Polynomial Coefficients) in NITF (National Imagery Transmission Format) 2.1 norm (RPC00B model) (Astrium-GEO 2012). So, the transformation from ground to image and vice versa is available via running RFM. In our experiments, the ground to image model (i.e. inverse model) has been run. Table 2 summarizes the results. The results are presented with respect to the bias compensation models. At first, the bias compensation is not applied (see "No" column). This means, if the RPCs distributed are used in an inverse model, the image coordinates of GCPs are estimated in such accuracy. When the adjustment run, the accuracies at GCPs are

\begin{tabular}{|l|l|c|c|}
\hline & $\begin{array}{l}\text { Bias Comp. } \\
\text { Model }\end{array}$ & No & Sim/Aff. \\
\cline { 2 - 4 } $\begin{array}{l}\text { Accuracies at } \\
\text { GCPs }\end{array}$ & $\begin{array}{l}\text { Standard } \\
\text { deviation } \\
( \pm \text { pixel })\end{array}$ & 7.4 & 1.1 \\
\cline { 2 - 4 } & $m_{0}( \pm$ pixel $)$ & 6.4 & 0.8 \\
\hline $\begin{array}{l}\text { Accuracies at } \\
\begin{array}{l}\text { FCPs } \\
(\mathrm{mp} \pm \text { pixel })\end{array}\end{array}$ & minimum & 2.5 & 0.3 \\
\cline { 2 - 4 } & maximum & 22.0 & 2.7 \\
\hline
\end{tabular}

Table 2. Summary of the accuracies at GCPs and FCPs for 1st degree RFM.

\pm 6.4 pixels, and the range of accuracies at FCPs is between 
$\pm 2.5-22.0$ pixels. In the second analysis, two bias compensation models suggested by Teo (2011) were preferred. As similar in IKONOS, QuickBird and OrbView-3, similarity and affine models result in equal accuracy, i.e. \pm 1.1 pixel for Pléiades. The accuracy after the adjustment is \pm 0.8 pixel at GCPs, and the figure condition at FCPs is ranging $\pm 0.3-2.7$ pixel.

Here the principles of figure condition concept must be remembered. Figure condition is an accuracy assessment method well known in geodesy. Especially in the geodetic transformations, the final transformation accuracy is estimated by this method with respect to the accuracy of both transformation parameters and the common (such as control) points. This method has been applied into datum transformation by Kutoğlu (2004) and successfully employed using 2D affine projection method for IRS-1C, SPOT-5 and Landsat TM images by Sertel et al. (2007). Topan and Kutoglu (2009) focuses on apply the concept for 3D affine projection model to assess IKONOS, QuickBird and OrbView-3 images. Topan (2013) also applied the figure condition analysis for RFM in order to evaluate the three image sets (i.e. IKONOS, QuickBird and OrbView-3). The readers can find the technical details in the publications mentioned above.

After this brief information, Figure 8 can be commented. In the case of Pléiades image evaluated here, the bias effect is seen from west to east direction with poor systematic effect (Figure 8. a). If the adjustment is run, the misfits become random (Figure 8. b). The best figure condition accuracy is estimated at the geometric centre of the GCPs, and the accuracy propagates through the outer of the centre accompanying with height change. If the height information is absent, the lines present a smooth pattern (Figure 8. c).

The second analysis was carried out with the application of the bias compensation methods. Both methods, i.e. similarity and affine models, produce the equal accuracy. The accuracy of the bias compensation is \pm 1.1 pixel without systematic pattern (Figure 9. a). When the adjustment runs, the accuracy at the GCPs is estimated as \pm 0.8 pixel, and the vector plot of misfits are in the similar direction of Figure 9. a (Figure 9. b). And the figure condition accuracy is resulted in $\pm 0.3-2.7$ pixels with the similar propagation pattern as in Figure 8.c (Figure 9. c).

The results can be compared with the findings of IKONOS, QuickBird and OrbView-3 given by Topan (2013). The standard deviation is higher than IKONOS, but lower than QuickBird and OrbView-3. This value is very close to
QuickBird. When the bias compensation is applied, the accuracy of compensation is lower than of all. The accuracy of the RPC refinement is higher than of all, but the range of figure condition accuracy is lower than of all. However, when the bias compensation is applied, the accuracy is lower than IKONOS and QuickBird, and higher than OrbView-3.

\section{CONCLUSION}

Pléiades opens a new era for the European based remote sensing activities with their sub-meter geometric resolution. Thanks to the Pléiades Users Group, two sets of three-stereo images are received covering Zonguldak test site. The first results of georeferencing accuracy assessment of panchromatic images have been presented in this paper. The findings demonstrate that a bias compensation method must be applied. After this, the sub-pixel accuracy can be easily reached at GCPs, and FCA is ranging with desired level. Because of the fact that the analysis run in this research is sensitive to the freedom of the adjustment, the second order RFM cannot be run. The types of analysis for Pléiades images will be varied thanks to the detailed field survey.

\section{REFERENCES}

Astrium-GEO. 2012. Pléiades Imagery User Guide.

Baillarin, S., J. Gasperi, C. Dabin, C. Panem, B. ChausserieLapree, J.-P. Gleyzes, P. Kubik, C. Latry, P. Floissac \& E. Hillairet. 2006. Remote Sensing Image Ground Segment Interoperability: PLEIADES-HR Case Study. In: IEEE International Conference on Geoscience and Remote Sensing Symposium, 928 - 931. Denver, USA.

Baillarin, S., C. Panem, L. Lebegue \& F. Bignalet-Cazalet. 2010. Pleiades HR Imaging System: Ground Processing and Products Performance, Few Months Before Launch. In (eds.): ISPRS TC VII Symposium - 100 Years ISPRS, eds. W. Wagner \& B. Székely, 51-55. Vienna, Austria.

Baudoin, A. 2004. Beyond SPOT 5: Pléiades, Part of the French-Italian Program ORFEO. In: International Archives of the Photogrammetry, Remote Sensing and Spatial Information Sciences, 260-267. Istanbul, Turkey.

Beaumet, G., G. Verfaillie \& M.-C. Charmeau (2011) Feasibility of Autonomous Decision Making on Board an Agile Earth-Observing Satellite. Computational Intelligence, 27.

Bernard, M., D. Decluseau, L.Gabet \& P. Nonin. 2012. 3D Capabilities of Pleiades Satellite. In: International Archives of

\begin{tabular}{|c|c|c|c|c|c|c|c|c|}
\hline \multicolumn{3}{|c|}{ Sensor and imagery format } & \multicolumn{2}{|c|}{ IKONOS Geo } & \multirow{2}{*}{\multicolumn{2}{|c|}{$\begin{array}{c}\text { QuickBird OrthoReady } \\
\text { Standard }\end{array}$}} & \multicolumn{2}{|c|}{ OrbView-3 Basic } \\
\hline \multirow{5}{*}{$\begin{array}{l}\text { Accuracies at } \\
\text { GCPs }\end{array}$} & \multicolumn{2}{|c|}{ \# GCP } & \multicolumn{2}{|c|}{22} & & & \multicolumn{2}{|c|}{30} \\
\hline & \multicolumn{2}{|c|}{ Bias Comp. Model } & No & Sim/Aff. & No & Sim/Aff. & No & Sim/Aff. \\
\hline & \multicolumn{2}{|c|}{$m_{o}( \pm$ pixel $)$} & 10.1 & 0.5 & 6.9 & 0.8 & 2.5 & 0.5 \\
\hline & \multirow[t]{2}{*}{ Adj. } & \# Freedom & \multicolumn{2}{|c|}{33} & \multicolumn{2}{|c|}{40} & \multicolumn{2}{|c|}{44} \\
\hline & & $m_{o}( \pm$ pixel $)$ & 3.1 & 0.6 & 5.2 & 0.7 & 3.9 & 1.9 \\
\hline \multirow{2}{*}{$\begin{array}{c}\text { Accuracies at } \\
\text { FCPs } \\
\left(m_{p} \pm \text { pixel }\right)\end{array}$} & \multicolumn{2}{|r|}{ minimum } & 1.2 & 0.2 & 1.9 & 0.3 & 1.2 & 0.6 \\
\hline & \multicolumn{2}{|r|}{ maximum } & 7.5 & 1.5 & 13.1 & 1.8 & 7.4 & 3.5 \\
\hline
\end{tabular}

Table 3. Summary of the accuracies at GCPs and FCPs for 1st degree RFM (Topan 2013) 
the Photogrammetry, Remote Sensing and Spatial Information Sciences. Melbourne, Australia.

Bignalet-Cazalet, F., S. Baillarin \& C. Panem (2012) Automatic and Generic Mosaicing of Multisensor Images: An Application to Pleiades HR. In: International Archives of the Photogrammetry, Remote Sensing and Spatial Information Sciences, XXXIX-B1, 509-512.

Blanchet, G., L. Lebegue, S. Fourest, C. Latry, F. Porez-Nadal, S. Lacherade \& C. Thiebaut. 2012. Pleiades-HR Innovative Techniques for Radiometric Image Quality Commissioning. In: International Archives of the Photogrammetry, Remote Sensing and Spatial Information Sciences, 513-518. Melbourne, Australia.

Boissin, M. B., A. Gleyzes \& C. Tinel. 2012. The Pléiades System and Data Distribution. In: IEEE International Geoscience and Remote Sensing Symposium, 7098 - 7101 Munich, Germany.

Delaunay, X., M. Chabert, V. Charvillat, G. Morin \& R. Ruiloba. 2008. Satellite Image Compression by Directional Decorrelation of Wavelet Coefficients. In: IEEE International Conference on Acoustics, Speech and Signal Processing, 11931196.

Flamanc, D. \& G. Maillet (2005) Evaluation of 3D City Model Production from Pleiades-HR Satellite Images and 2D Ground Maps. In: International Archives of the Photogrammetry, Remote Sensing and Spatial Information Sciences, XXXVI8/W27.

Fourest, S., P. Kubik, L. Lebègue, C. Déchoz, S. Lacherade \& G. Blanchet (2012) Star-Based Methods for Pleiades HR Commissioning. In: International Archives of the Photogrammetry, Remote Sensing and Spatial Information Sciences, XXXIX-B1, 531-536.

Gleyzes, M. A., L. Perret \& P. Kubik (2012) Pleiades System Architecture and Main Performances. In: International Archives of the Photogrammetry, Remote Sensing and Spatial Information Sciences, XXXIX-B1, 537-542.

Greslou, D., F. d. Lussy, J. M. Delvit, C. Dechoz \& V. Amberg (2012) Pleiades-HR Innovative Techniques for Geometric Image Quality Commissioning. In: International Archives of the Photogrammetry, Remote Sensing and Spatial Information Sciences, Volume XXXIX-B1.

J. M. Delvit, D. Greslou, V. Amberg, C. Dechoz, F. d. Lussy, L. Lebegue, C. Latry, S. Artigues \& L. Bernard (2012) Attitude Assessment Using Pleiades-HR Capabilities. In: International Archives of the Photogrammetry, Remote Sensing and Spatial Information Sciences, XXXIX-B1, 525-530.

Kapnias, D., P. Milenov \& S. Kay. 2008. Guidelines for Best Practice and Quality Checking of Ortho Imagery. European Commission, Joint Research Centre, Institute for the Protection and Security of the Citizen.

Kutoğlu, H. (2004) Figure Condition in Datum Transformation. Journal of Surveying Engineering, 130, 138141.

Lachérade, S., S. Fourest, P. Gamet \& L. Lebègue (2012) Pleiades Absolute Calibration : Inflight Calibration Sites and Methodology. In: International Archives of the
Photogrammetry, Remote Sensing and Spatial Information Sciences, XXXIX-B1, 549-554.

Lamard, J.-L., C. Gaudin-Delrieu, C. R. David Valentini, T. Tournier \& J.-M. Laherrere. 2004. Design of the High Resolution Optical Instrument for the Pleaides HR Earth Observation Satellites. In: 5th International Conference on Space Optics (ICSO 2004) ed. 2004, 149-156. Toulouse, France.

Latry, C., S. Fourest \& C. Thiebaut (2012) Restoration Technique for Pleiades-HR Panchromatic Images. In: International Archives of the Photogrammetry, Remote Sensing and Spatial Information Sciences, XXXIX-B1, 555-560.

Lebegue, L., D. Greslou, F. Delussy, S. Fourest, C. Latry, P. Kubik \& J.-M. Delvit. 2010. Pleiades-HR Image Quality Commissioning Foreseen Methods. In: International Geoscience and Remote Sensing Symposium 2010, 1675-1678. Hawaii.

Lebègue, L., D. Greslou, F. d. Lussy, S. Fourest, B. G, C. Latry, L. Lachérade, J. M. Delvit, P. Kubik, C. Déchoz, V. Amberg \& F. Porez-Nadal (2012) Pleiades-HR Image Quality Commissioning. In: International Archieves of the Photogrammetry, Remote Sensing and Spatial Information Sciences, XXXIX-B1, 561-566.

Lussy, F. d., D. Greslou, C. Dechoz, V. Amberg, J. M. Delvit, L. Lebegue, G. Blanchet \& S. Fourest (2012) Pleiades HR In Flight Geomatrical Calibration: Location and Mapping of the Focal Plane. In: International Archives of the Photogrammetry, Remote Sensing and Spatial Information Sciences, XXXIX-B1, 519-523.

Lussy, F. d., P. Kubik, D. Greslou, V. Pascal, P. Gigord \& J. P. Cantou. 2005. Pleiades-HR Image System Products and Quality, Pleiades-HR Image System Products and Geometric Accuracy. In: ISPRS Hannover Workshop, 6 pages. Hannover, Germany.

Panem, C., F. Bignalet-Cazalet \& S. Baillarin (2012) PleiadesHR System Products Performance After in-Orbit Commissioning Phase. In: International Archieves of the Photogrammetry, Remote Sensing and Spatial Information Sciences, XXXIX, 567-572.

Poli, D., F. Remondino, E. Angiuli \& G. Agugiaro. 2013. Evaluation of Pleiades-1A Triplet on Trento Testfield. In: International Archives of the Photogrammetry, Remote Sensing and Spatial Information Sciences, ISPRS Hannover Workshop 2013, Volume XL-1/W1. Hannover, Germany.

Sertel, E., S. H. Kutoglu \& S. Kaya (2007) Geometric correction accuracy of different satellite sensor images: application of figure condition. International Journal of Remote Sensing, 28, 4685-4692.

Teo, T.-A. (2011) Bias Compensation in a Rigorous Sensor Model and Rational Function Model for High-Resolution Satellite Images. Photogrammetric Engineering \& Remote Sensing, 77, 1211-1220.

Topan, H. (2013) First Experience with Figure Condition Analysis Aided Bias Compensated Rational Function Model for Georeferencing of High Resolution Satellite Images. Journal of the Indian Society of Remote Sensing.

Topan, H. \& H. S. Kutoglu (2009) Georeferencing Accuracy Assessment of High-Resolution Satellite Images Using Figure 
Condition Method. IEEE Transactions on Geoscience and Remote Sensing, 47, 1256-1261.

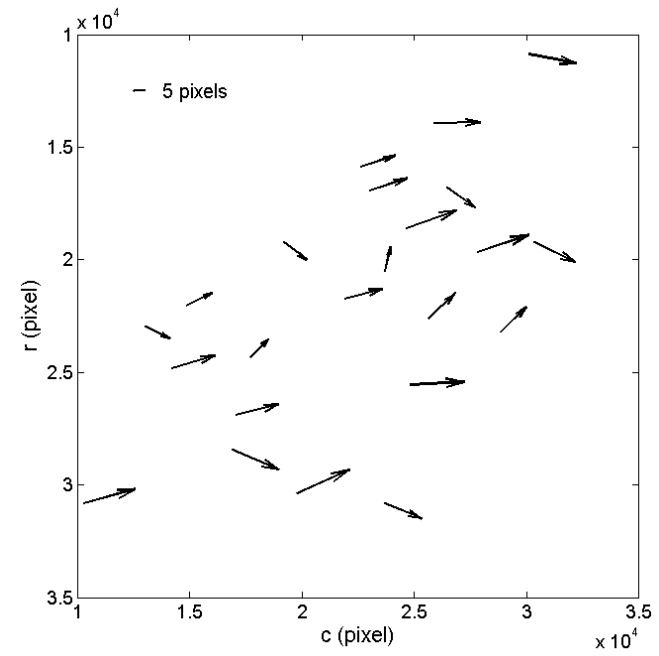

a) $\operatorname{Bias}\left(m_{0}= \pm 7.4\right.$ pixel $)$

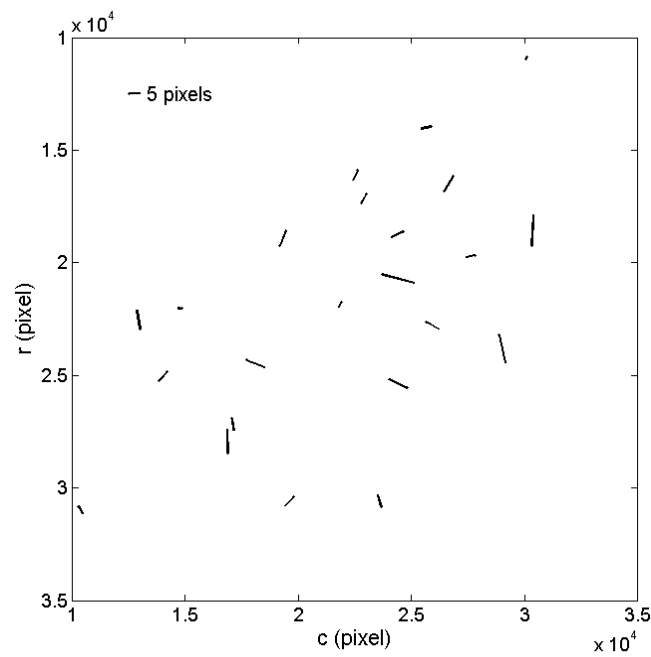

b) $1^{\text {st }}$ degree RFM without bias compensation $\left(m_{0}= \pm 6.4\right.$ pixels $)$

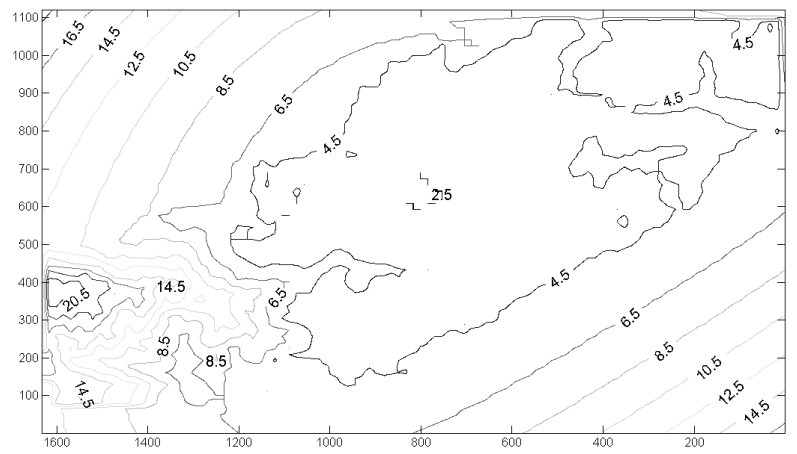

c) FC accuracy without bias compensation for 1st degree RFM (range: $\pm 2.5-22.0$ pixels)

Figure 8. Results for Image 1 without bias compensation.

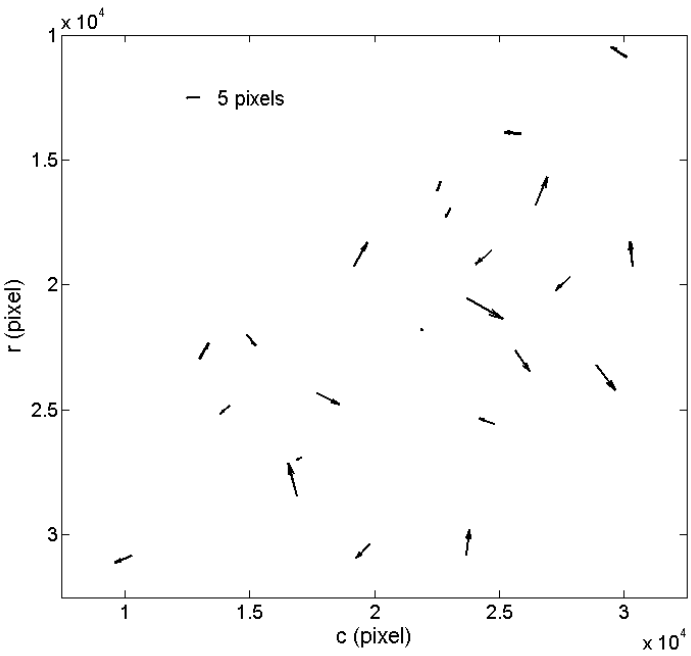

a) Bias compensation $\left(m_{0}= \pm 1.1\right.$ pixel $)$

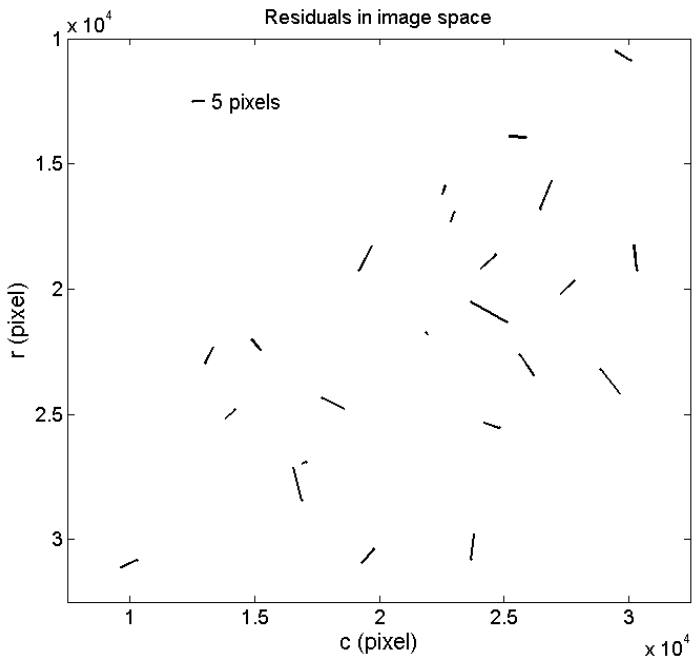

b) $1^{\text {st }}$ degree RFM with bias compensation $\left(m_{0}= \pm 0.8\right.$ pixel)

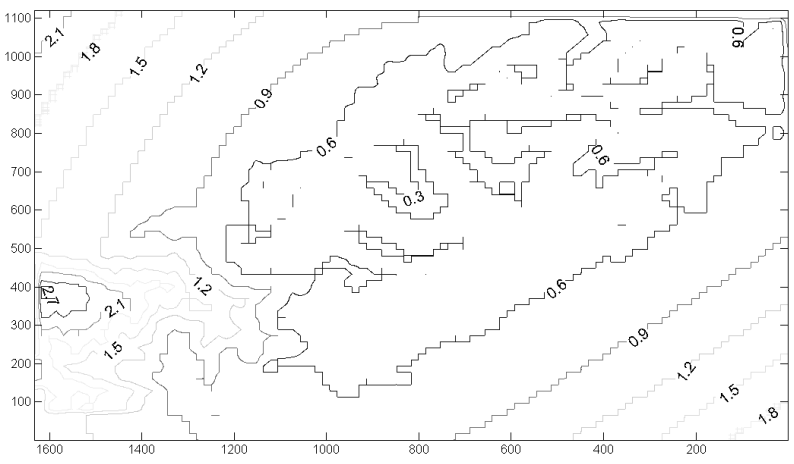

c) FC accuracy with bias compensation for 1st degree RFM (range: $\pm 0.3-2.7$ pixels)

Figure 9. Results for Image 1 with bias compensation. 